MITTEILUNGEN

\title{
https://doi.org/10.1007/s00350-021-5980-1
}

\section{DGMR ehrt Prof. Dr. med. Toni Graf-Baumann}

Die Deutsche Gesellschaft für Medizinrecht e. V. hat Herrn Prof. Dr. med. Toni Graf-Baumann zu seinem Ehrenmitglied ernannt. Mit dieser Ehrung sind der Dank und die Anerkennung für seine langjährige Mitgliedschaft seit der Gründung der DGMR und seine großen Verdienste um das Medizinrecht und die DGMR selbst verbunden. Ohne sein stetiges Eintreten für eine Vertiefung der interdisziplinären Beziehungen zwischen Recht und Medizin mit dem Ziel eines besseren gegenseitigen Verständnisses wäre der DGMR über die Jahre hinweg nicht die Anerkennung zuteil geworden, die sie auch heute noch in Wissenschaft und Praxis genießt.

Auf Initiative von Graf-Baumann ist die DGMR im September 1982, also vor fast 40 Jahren, in Heidelberg aus der Taufe gehoben worden. Er selbst hat ihr als Präsident in den Jahren von 1992 bis 1996 vorgestanden und später das verantwortungsvolle und arbeitsreiche Amt des Schatzmeisters

Rechtsanwalt Dr. iur. Albrecht Wienke,

Fachanwalt für Medizinrecht, Wienke \& Becker - Köln,

Sachsenring 6, 50677 Köln, Deutschland übernommen. Er hat immer wieder die Workshops und Publikationen der DGMR mit seinen Ideen und Erfahrungen bereichert und durch großes Engagement gefördert. Für seine herausragenden Leistungen für die Ärzteschaft ist er mit der Ehrenplakette der Landesärztekammer Hessen ausgezeichnet worden. Gleichermaßen hat er die Deutsche Gesellschaft für Manuelle Medizin mit ihren Ärzteseminaren, die Deutsche Gesellschaft für Osteopathische Medizin, die Deutsche Schmerzgesellschaft und andere ärztliche Vereinigungen fachlich und strategisch bei ihren jeweiligen Anliegen unterstützt. Sein besonderes Augenmerk galt daneben dem internationalen Sport, dem er als Mitglied in verschiedenen sportmedizinischen Kommissionen des DFB, der FIFA und dem IOC gedient hat. Sein außergewöhnliches Engagement in all diesen Bereichen war und ist vorbildlich und bewundernswert. Die DGMR drückt ihren Dank mit der Verleihung der Ehrenmitgliedschaft an Herrn Prof. Dr. med. Graf-Baumann aus.

Für die DGMR e. V.

Der Präsident

Köln im Juni 2021 